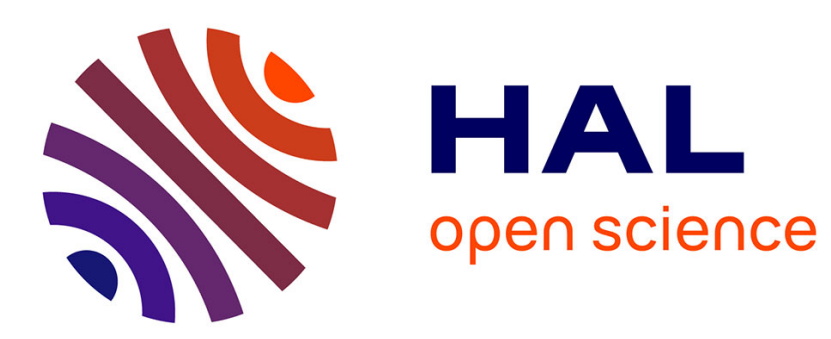

\title{
Electrochemiluminescence on-a-chip: towards a hand-held electrically powered optofluidic source.
}

Sébastien Méance, Jean Gamby, Mathilde Faure, Qingli Kou, Anne-Marie Haghiri-Gosnet

\section{- To cite this version:}

Sébastien Méance, Jean Gamby, Mathilde Faure, Qingli Kou, Anne-Marie Haghiri-Gosnet. Electrochemiluminescence on-a-chip: towards a hand-held electrically powered optofluidic source.. Talanta, 2014, 129, pp.150-154. 10.1016/j.talanta.2014.05.026 . hal-01079966

\section{HAL Id: hal-01079966 https://hal.science/hal-01079966}

Submitted on 19 Nov 2014

HAL is a multi-disciplinary open access archive for the deposit and dissemination of scientific research documents, whether they are published or not. The documents may come from teaching and research institutions in France or abroad, or from public or private research centers.
L'archive ouverte pluridisciplinaire HAL, est destinée au dépôt et à la diffusion de documents scientifiques de niveau recherche, publiés ou non, émanant des établissements d'enseignement et de recherche français ou étrangers, des laboratoires publics ou privés. 


\title{
Electrochemiluminescence on-a-chip: towards a hand-held electrically powered optofluidic source
}

\author{
Sébastien Méance ${ }^{\mathrm{a}}$, Jean Gamby ${ }^{\mathrm{b}, \mathrm{c}, \dagger}$, Mathilde Faure $^{\mathrm{b}, \mathrm{c}}$, Qingli Kou ${ }^{\mathrm{d}, e}$ and Anne-Marie \\ Haghiri-Gosnet ${ }^{\mathrm{a}}$ \\ ${ }^{a}$ CNRS, Laboratoire de Photonique et de Nanostructures, UPR20, route de Nozay, Marcoussis \\ 91460, France \\ ${ }^{b}$ CNRS, UMR 8235, LISE, F-75005, Paris, France \\ c Sorbonne Universités, UPMC Univ Paris 06, UMR 8235, Laboratoire Interfaces et Systèmes \\ Electrochimiques, F-75005, Paris, France \\ ${ }^{d}$ Université Paris-Sud, Institut des Sciences Moléculaires ISMO, UMR 8214, Bâtiment 350, 91405 \\ Orsay Cedex, France \\ ${ }^{e}$ CNRS, UMR 8214, ISMO, F-91405, Orsay, France
}

\footnotetext{
${ }^{\dagger}$ Corresponding author :

jean.gamby@upmc.fr

tel: +33144273640 fax: +33144274074 


\begin{abstract}
We report a microfluidic platform that integrates several parallel optical sources based on electrochemiluminescence (ECL) of 9,10-diphenylanthracene (DPA) as luminophore agent. The annihilation of DPA radicals provides a low wavelength emission at $\lambda=430 \mathrm{~nm}$ in the blue-visible range. By varying the distance between electrodes for each ECL integrated source, this glass/PDMS/glass platform enabled a systematic investigation of the main electrochemical parameters involved in ECL. These parameters have been studied either in a static mode or in a dynamic one. Even at slow flow rate $\left(\sim 2 \mu \mathrm{ls}^{-1}\right)$, the renewal of electroactive species could be easily promoted inside the microfluidic channel which gives rise to a stable optical intensity for several minutes. Compared with traditional optically pumped dye sources, this microfluidic system demonstrates that ECL can be easily implemented on chip for producing much compact optofluidic sources. Such simply electrically powered system-on-chip would surely encourage the future of hand-held $\mu$ TAS devices with integrated fast detection and embedded electronics.
\end{abstract}

Keywords: Optofluidics; Electrochemiluminescence; 9,10-diphenylanthracene; Cyclic voltammetry. 


\section{Introduction}

Optofluidics refers to a class of devices that integrate optics and microfluidics on a same chip. New optical properties can be simply obtained by manipulating fluids with a small volume of analytes about few nanoliters. Concerning optofluidic integration of fluidic and optical components on the same chip, a lot of works have focused on the effective traditional optical detection methods. Indeed, measurements of absorption, [1-3] scattering, [4] fluorescence, [5-10] variation of the refractive index ranging from Mach-Zehnder interferometer [11-13] to surface plasmon resonance (SPR) including whispering gallery mode [14-17] (WGM), and Raman spectrometry [18,19] offer many advantages in terms of selectivity and limit of detection [20,21]. In parallel, miniaturization and integration of coherent optical sources have raised an increasing interest during the past few years [22, 23]. In this context, microfluidic dye lasers appear to be attractive as they can perform high sensitive detection with a small volume of reagent. However, such systems generally require a frequency-doubled pulsed Nd:YAG laser and optics for optical pumping. This optical chain constitutes a bulky system outside the chip that has to be carefully coupled to the microfluidic device [24-25]. Scientific efforts are thus pursued for a better integration of planar light sources [26].

To increase the autonomy and the portability of such integrated sources, we present in this work an alternative method to the traditional optical pumping. An electrically pumped light source can be directly incorporated on a chip thanks to electrochemiluminescence (ECL). This ECL-based method, which consists in producing light from excited states of an organic luminophore, is fully compatible with microfluidic technologies.

The annihilation of 9,10-diphenylanthracene (DPA) radicals provides a low wavelength emission in the blue visible range at $\lambda=430 \mathrm{~nm}$. This phenomenon involves electron transfer reactions between oxidized and reduced species. The general mechanism is described below [27]:
DPA - $\mathrm{e}^{-} \rightarrow \mathrm{DPA}^{\bullet+}$
(Anode oxidation, cation radical formation) 
$\mathrm{DPA}^{\bullet+}+\mathrm{DPA}^{\bullet-} \rightarrow \mathrm{DPA}^{*}+\mathrm{DPA} \quad$ (Annihilation, excited state formation)

$\mathrm{DPA}^{*} \rightarrow \mathrm{DPA}+\mathrm{h} v \quad$ (Light emission)

This reaction has been well described for the last forty years, and this system has been well characterized in terms of ECL efficiencies, stabilities, and mechanisms [28-30]. By applying a potential between the electrodes, the ground-state DPA molecules are respectively oxidized and reduced at the anode and the cathode forming one radical cation $\left(\mathrm{DPA}^{\bullet+}\right)$ and one radical anion $\left(\mathrm{DPA}^{\bullet-}\right)$. By diffusion radicals species meet, and excited state molecules $\left(\mathrm{DPA}^{*}\right)$ are generated as the result of the annihilation reaction. Finally light emission occurs from the first excited DPA singlet (DPA ${ }^{*}$ ) when the molecule returns to its initial state.

In this paper we propose the integration and the characterisation of such miniaturized independent ECL sources on a chip. The purpose of this study is to check if the DPA annihilation reaction could be implemented inside a hand-held microfluidic chip in order to validate ECL as a promising route for electrically powered light sources.

\section{Experimental}

\subsection{Chemicals}

The 9,10-diphenylanthracene (DPA, 97\%) was used as an organic luminophore. The N,Ndimethylformamide (DMF, 95\%) was used as received i. e. without distillation and the tetra-n-butylammoniumtetrafluoroborate $\left(\mathrm{TBABF}_{4}, 99 \%\right)$ as the supporting electrolyte. The solutions were previously degassed by bubbling dry nitrogen to remove oxygen prior to introduction into the microchip. 


\subsection{Electrochemical measurements}

Electrochemical measurements were performed using a Biologic SP-300 electrochemical analysis system with EC-lab software. The electrochemical study based on the DPA cyclic voltammetry $(\mathrm{CV})$ has been performed in a conventional macro-cell with a three electrodes configuration. The reference and the counter electrodes were a saturated calomel electrode (SCE) and a platinum grid (Pt), respectively. The working electrode was a gold with a diameter equal to $125 \mu \mathrm{m}$. The $\mathrm{CV}$ scan rate has been varied from $0.1 \mathrm{Vs}^{-1}$ to $2 \mathrm{Vs}^{-1}$. The deoxygenated electrolytic solution was a dimethylformalmide (DMF) solvent containing $0.1 \mathrm{molL}^{-1}$ of $\mathrm{TBABF}_{4}$.

\subsection{Microchip fabrication}

The fabrication process uses an original silicon "photosensitive PDMS" resist. $200 \mathrm{~nm}$ thick platinum microelectrodes were first patterned on the lower glass substrate (D263 Borosilicate) by conventional UV lithography and lift-off processes. Each couple of microelectrodes is spaced by a separation distance $d$ ranging from $2 \mu \mathrm{m}$ to $15 \mu \mathrm{m}$ in a single microfluidic architecture (Scheme 1). The $16 \mu \mathrm{m}$ thick microfluidic channel was then patterned with the UV sensitive "PDMS" resist (WL-5150 Dow Corning) and later developed in a mesitylene bath.

After bonding of the upper glass substrate at high pressure $(2.07 \mathrm{MPa})$, the final device was sealed and connected onto a printed circuit board (PCB) for fast interfacing with experimental setup (Figure 1). Each optofluidic device with 4 channels and 4 interelectrode distances allows parallel ECL experiments to study how luminescence efficiency is affected by the experimental parameters such as the electrode distance, $d$, the voltage and the volumetric flow rate, $F_{v}$.

\subsection{Microfluidic electrochemiluminescent measurements}

A computer controlled syringe pump model NEMESYS (Cetoni), with a $10 \mathrm{~mL}$ glass syringe supplied the solution at a constant volumetric flow rate. The voltage ramp for cyclic voltammetry and the voltage step for chronoamperometry were supplied by a PL330DP (ThurlbyThandar Instruments) DC power supply. A 34970A (Agilent) 16-channel multiplexer enabled to select any couple of microelectrodes out of the 16 ones available on 
chip. An ammeter (Agilent 34411A) connected in series with the generator and the microelectrodes measured the electric current. All electrical apparatus were linked to a PC with GPIB bus (IEEE-488) interface card. They were controlled and monitored under a Matlab (Mathworks) environment. Light was collected via a multimode optical fiber (125 $\mu \mathrm{m})$. Its spectrum was recorded by an optical spectrometer (USB2000 Ocean Optics). A photomultiplier tube (PMT, Hamamatsu H6779-20) measured the intensity of ECL.

\section{Results and discussion}

\subsection{DPA characterization in macrocell}

Detailed reports on electrochemistry of DPA are available in the literature and will be helpful in this discussion. Preliminary to chip ECL measurements, electrochemical reactions were tested in DPA in $0.1 \mathrm{molL}^{-1} n-\mathrm{Bu}_{4} \mathrm{NBF}_{4}$ in DMF solution (Figure 2). This DPA electroactivity can be relatively complex in a large potential window. Savéant et. al. [31] have observed an irreversibility of the second cathodic wave for DPA while the two cathodic waves are reversible in the case of anthracene. To avoid the formation of di-anion $\mathrm{DPA}^{2--}$ radicals [31], the potential window has thus been reduced to the range $[-2.0 \mathrm{~V},-1.8$ $\mathrm{V}]$, where the anion radical DPA ${ }^{\bullet-}\left(\mathrm{DPA}+\mathrm{e}^{-}->\mathrm{DPA}^{\bullet-}\right.$ at $\left.-1.8 \mathrm{~V} / \mathrm{SCE}\right)$ is observed for the reversible cathodic wave and the cation radical $\mathrm{DPA}^{\bullet+}\left(\mathrm{DPA}->\mathrm{DPA}^{\bullet+}+\mathrm{e}^{-}\right.$at $\left.1.3 \mathrm{~V} / \mathrm{SCE}\right)$ for the irreversible anodic wave of $5 \mathrm{mM}$ DPA in DMF.

The reversibility of the reduction wave has been verified through the variation of the scan rate. The shape of the DPA voltammogram remains reversible in spite of the variation of the scan rate. Indeed, the corresponding potential difference value $\Delta E_{\mathrm{p}}=E_{\mathrm{pc}}-E_{\mathrm{pa}}$ is about $0.067 \mathrm{~V}$ vs. SCE for a scan rate of $0.1 \mathrm{Vs}^{-1}$ and, respectively, $0.071 \mathrm{~V}$ vs. SCE for a scan rate of $2 \mathrm{Vs}^{-1}$. These values are in agreement with the $\Delta E_{\mathrm{p}}$ value of a reversible one-electron reaction. However, the ratio between the anodic and cathodic peaks was found different to 1 indicating moderate stability. This tendency is not surprising and it is mainly observed when the concentration of NDA used increases (higher than $1.5 \mathrm{mM}$ ) [32]. From this, the diffusion coefficient of DPA reduction can also be deduced from the proportionality 
between the square root of the scan rate and the peak current as in the well-known relation in the Nernstian case [33]:

$$
i_{p}=0.446 n F S C^{0} \sqrt{D} \sqrt{\frac{F V}{R T}}
$$

where $i_{p}$ represents the peak current value (A), $n=1$ number of exchanged electrons, $F$ is the Faraday constant $\left(\mathrm{C} \mathrm{mol}^{-1}\right), C^{0}$ the bulk concentration of the species $\left(\mathrm{mol} \mathrm{cm}^{-3}\right), S$ is the electrode area $\left(\mathrm{cm}^{2}\right), D$ the diffusion coefficient $\left(\mathrm{cm}^{2} \mathrm{~s}^{-1}\right), v$ the scan rate $\left(\mathrm{Vs}^{-1}\right)$.

The diffusion coefficient was determined to $6.9610^{-6} \mathrm{~cm}^{2} \mathrm{~s}^{-1}$ through the linear variation slope of the current peak intensity against the square root of the scan rate. This value is close similar to the one mentioned in the literature for DPA in DMF [34].

However, as mentioned previously, the chemical irreversibility of the oxidation wave has been observed at positive potentials for different scan rates (Figure 2). Indeed, in our non anhydrous conditions the free radical cation is not stable and it reacts with traces of water to form trans-9,10-dihydro-9,10-diphenyl-anthracene. Additionally, the broad humps are attributed to the background oxidation products (residuals impurities in DMF) [28]. As observed in Figure 2, the anodic reaction is an electrochemical-chemicalelectrochemical (ECE) mechanism where the irreversibility is due to the chemical reaction corresponding to hydroxylation [35-37].

\subsection{Electrochemiluminescence in the optofluidic chip}

After this preliminary study in the macrocell, ECL was then measured in the microfluidic chips with the geometry described in the Scheme 1. For a better correlation, electrical and optical characterizations have been performed simultaneously. A two-electrode configuration is preferable to have symmetry between the cathodic and anodic waves on the potential window. Potential difference was applied between these two electrodes without any reference electrode. The measured potentials have thus to be considered as floating potentials.

\subsubsection{Electrical characterizations}

In a preliminary experiment the $25 \mathrm{mM}$ DPA was selected to have the same conditions used in Horiuchi work [30]. A linear potential sweep was applied to the microelectrodes in order 
to record CV curves within the chip. Figure 3 shows a typical voltammogram where the potential is first scanned linearly until DPA starts to be oxidized near 2.5 Volts when anodic current appears. ECL light emission can be observed at 3.3 Volts (blue coloured right area in Figure 3). In a second step, the potential is scanned towards negative potentials. DPA starts to be reduced near -2.5 Volts when cathodic current appears. ECL light emission can be observed at $-3.3 \mathrm{~V}$ (blue coloured left area in Figure 3). As it can be observed in the inset of Figure 3, the blue ECL light is visible across the whole microchannel (width $=150 \mu \mathrm{m}$ ) between the two electrodes as well as on top of the two large microelectrodes (Scheme 1).

In brief, our microchip with several pairs of electrodes (two-electrode system) there is no reference electrode (e.g. as SCE in traditional system). One platinum electrode plays the role of the counter electrode and the other platinum is the working electrode. The two electrodes are in the same material and have the same area. As a consequence the potential of the cathode and the anode are set on that given by DPA reduction and DPA oxidation, respectively. That is confirmed through the symmetrical response obtained on the $\mathrm{I} / \mathrm{E}$ potential window $[-3.3 \mathrm{~V},+3.3 \mathrm{~V}]$. As expected in this symmetrical device, all the unstable radical species created from the ground-state DPA molecules, at the anode and the cathode respectively, diffuse to generate the excited DPA (DPA*) and then the blue ECL light in the whole channel.

To study the time stability of the ECL reaction in the chip, the evolution of the current as function of time has been recorded at different flow rates. Firstly, measurements were performed in static (red curve of the Figure 4) and secondly under a continuous flow rate $F_{\mathrm{v}}$ (green curve). For a planar microelectrode the well-known Cottrell equation can be used. Indeed, the static current is proportional to $t^{-1 / 2}$ indicating that the measured chronoamperometric current tends to zero when time increases:

$$
i(t)=n F S C^{0} \sqrt{\frac{D}{\pi t}}
$$

where $n, F, S, C^{0}$ and $D$ were parameters defined above and $t$ represents the time (s).

The red dash curve in Figure 4 represents this computed equation and fit in good agreement with the experimental values in the static regime $\left(F_{\mathrm{v}}=0\right)$. Since the ECL reaction is in 
agreement with the Cottrell equation, the diffusion-controlled reaction is observed to be not affected by the liquid confinement inside the microchannel.

Secondly, we also show that a small flow rate of $0.1 \mu \mathrm{L} \mathrm{s}^{-1}\left(6 \mu \mathrm{L} \mathrm{min}{ }^{-1}\right)$ is sufficient to get higher intensity after five minutes as exposed by the small slope in the linear part of the green curve (Figure 4). The Levich equation models the mass-transport limiting current in hydrodynamic voltammetry. According to Compton et. al., [38] the limiting current flowing at a microband electrode is given by:

$$
i_{\lim }=0.925 n F C^{0} w\left(x_{e} D_{0}\right)^{2 / 3}\left(\frac{F_{v}}{h^{2} d}\right)^{1 / 3}
$$

where $w$ the width of the electrode $(\mathrm{cm}), x_{e}$ the length of the electrode $(\mathrm{cm}), F_{v}$ the volumetric flow rate $\left(\mathrm{cms}^{-1}\right), h$ the channel depth $(\mathrm{cm})$ and $d$ the channel width $(\mathrm{cm})$.

The Levich current calculated should be here of $6.55 \times 10^{-5}$ A. From our ammeter measurements, we obtain an experimental current of $3.5 \times 10^{-5} \mathrm{~A}$, which is about two times less than the expected Levich value. This is probably due to the existing hydroxylation reaction which takes place in the microdevice.

This demonstrates that among the numerous methods involving forced convection (rotating disks, rotating wires, streaming mercury electrodes...), microfluidics and its laminar flow properties offer significant advantages over other hydrodynamic methods [39]. Indeed, to achieve intense continuous Faradic current at a constant high value, increasing the flow rate is thus a practical way easy to implement in microfluidic devices.

\subsubsection{Simultaneous ECL and optical measurements}

The optical spectra have been first recorded under a moderate flow of DPA solution $(0.5 \mu 1$ $\mathrm{s}^{-1}$ ). The maximum intensity recorded both for ECL and fluorescence spectra peaks at the same wavelength $(430 \mathrm{~nm})$. ECL and fluorescence emission spectra are fully superimposed which confirms that the same electronic states are engaged in the ECL mechanism.

Figure 5 shows the corresponding optical measurement of ECL intensity based on photomultiplier tube (PMT) (in green) during the electrochemical oxidation of $15 \mathrm{mM}$ of DPA on microelectrode (in red). The PMT voltage that is proportional to the ECL light power is reported while the electrochemical current obtain was unfolded according to time 
(top axis in the Figure5) in order to compare the two experimental measurements. As expected, at the $3.3 \mathrm{~V}$ potential value when ECL starts, both electrical current and PMT voltage abruptly increase. This confirms that the electrochemical measured current reflects perfectly the number of emitted photons.

Finally for light source applications, the most important point concerns power light stability. In order to check this stability, we have simultaneously recorded optical and electrical chronoamperometric curves for DPA (Figure 6). The 1.04 ratio for the limited Levich electric current calculated $\left(4.37 \times 10^{-5} \mathrm{~A}\right.$ and $\left.4.19 \times 10^{-5} \mathrm{~A}\right)$ for $d=2 \mu \mathrm{m}$ and $d=10$ $\mu \mathrm{m}$, respectively, is in the same order of magnitude as the 1.30 ratio for the limited current measured $1.94 \times 10^{-5} \mathrm{~A}$ and $1.49 \times 10^{-5}$ for $d=2 \mu \mathrm{m}$ and $d=10 \mu \mathrm{m}$, respectively. This small electric current ratio for electrodes spacing of $d=2 \mu \mathrm{m}$ and $d=10 \mu \mathrm{m}$ is totally different of light power ratio (photomultiplier output voltage). So, for a 1.30 electric current ratio, the light power ratio is about $2.33(-0.07$ and $-0.03 \mathrm{~V}$ respectively for $d=2 \mu \mathrm{m}$ and $d=10 \mu \mathrm{m})$ and confirms the hypothesis that the space between the two electrodes is an important parameter for the annihilation between highly reactive radicals.

\section{Conclusions}

Used synergistically, optics and fluidics take advantage of the microfluidic devices for photonics and contribute significantly to the advances in $\mu$ TAS. In the last decade, the community focuses its efforts in developing on-a-chip optofluidic methods for a wide variety of applications in the field of analytical chemistry, biology, and biomedical research. To increase the autonomy and portability of such integrated systems, we have proposed to integrate the liquid organic light source by exploiting ECL. After studying ECL mechanisms of DPA diluted in DMF based on a conventional electrochemical macrocell, ECL was then studied inside the microfluidic chip. In conclusion, we have demonstrated that ECL can be successfully implemented in an integrated microfluidic device with electrodes spaced by a few microns working at low flow rate. Such independent miniaturized sources exhibit very good power light stability and they may represent a novel route for massive implementation in analytical $\mu$ TAS. Through its ability to use small quantities of dyes and to convert electrical energy into optical signal, we have 
shown that ECL appears to be a promising phenomenon for optical microsystems. Since such fluidic organic optical source can be simply electrically powered with low energy consumption, we trust in its high potential to develop portable $\mu$ TAS with embedded electronics.

\section{Acknowledgements}

This work was financially supported by the University of Paris-Sud and by the French ANR (Agence Nationale de la Recherche) in the context of the P2N "DIMIPOLE" project. 


\section{References}

[1] Mogensen, K. B., Eriksson, F., Gustafsson, O., Nikolajsen, R. P. H., Kutter, J. P.,2004, Electrophoresis, 25, 3788-3795.

[2] Grumann, M., Steigert, J.,Riegger, L., Moser, I., Enderle, B., Riebeseel, K., Urban, G., Zengerle, R., Ducree, J., 2006, Biomed. Microdevices., 8, 209-214.

[3] Zhu, L., Lee, C., DeVoe, D., 2005, Lab Chip, 6, 115-120.

[4] Witek, M. A., Wie, S., Vaidya, B., Adams, A. A., Zhu, L., Stryjewski, W., McCarley,

R. L., Soper, S. A., 2004, Lab Chip, 4, 464-472.

[5] Yeh, H. C., Puleo, C. M., Lim, T. C., Ho, Y. P., Giza, P. E., Huang, R. C. C., Wang, T.

H., 2006, NucleicAcids Res., 34, 144-152.

[6] Gong, M., Wehmeyer, K. R., Limbach, P. A., Arias, F., Heineman, W. R., 2006, Anal. Chem., 78, 3730-3737.

[7] Dishinger, J. F., Kennedy, R. T., 2007, Anal.Chem., 79, 947-954.

[8] Yue, S., Xue-Feng, Y., 2006, J. Chromatogr. A., 1117, 228-233.

[9] Yang, S. Y., Hsiung, S. K., Hung, Y. C., Chang, C. M., Liao, T. L., Lee, G. B., 2006, Meas. Sci. Technol., 17, 2001.

[10] Yamaguchi, N., Ohba, H., Nasu, M., 2006, Lett. Appl. Microbiol., 43, 631-636.

[11] Luff, B., Wilkinson, J. S., Piehler, J., Hollenbach, U., Ingenhoff, J., Fabricius, N., 1998, J. Lightwave.Techn., 16, 583.

[12] Prieto, F., Sepúlveda, B., Calle, A., Llobera, A., Domínguez, N. C., Abad, A., Montoya, A., Lechuga, L. M., 2003, Nanotechnology, 14, 907.

[13] Ymeti, A., Greve, J., Lambeck, P. V., Wink, T., Van Hovell, S.W.F.M., Beumer, T. A. M., Wijn, R. R., Heideman, R. G., Subramaniam, V., Kanger, J. S.,2007, Nano Letters, 7, 394-397.

[14] Arnold, S., Khoshsima, M., Teraoka, I., Holler, S. Vollmer, F., 2003, Opticsletters, 28, 272-274.

[15] Matsko, A. B., Ilchenko, V. S., 2006, IEEE J. Sel. Top. Quantum Electron., 12, 3-14.

[16] Ilchenko, V. S., Matsko, A. B., 2006, IEEE J. Sel. Top. Quantum Electron., 12, 15-32.

[17] Fainman,Y., Psaltis, D., 2009, Optofluidics: fundamentals, devices, and applications, McGraw-Hill Professional. 
[18] Kneipp, K., Kneipp, H., Itzkan, I., Dasari, R. R., Feld, M. S., 2002, J. Phys.: Condens. Matter., 14, R597.

[19] Connatser, R. M., Riddle, L. A., Sepaniak, M. J., 2004, J. Sep. Sci., 27, 1545-1550.

[20] Hunt, H. C.,Wilkinson, J. S., 2008, Microfluidics and Nanofluidics, 4, 53-79.

[21] Erickson, D., Mandal, S., Yang, A. H. J., Cordovez, B., 2008, Microfluidics and Nanofluidics, 4, 33-52.

[22] Li, Z. Y., Psaltis, D., 2008, Microfluidics and Nanofluidics, 4, 145-158.

[23] Aubry, G., Kou, Q., Soto-Velasco, J., Wang, C., Méance, S., He, J., Haghiri-Gosnet, A.-M., 2011, Appl. Phys. Lett., 98, 111111.

[24] Helbo, B., Kristensen, A., Menon, A., 2003, J. Micromecn. Microengineer., 13, $307-$ 311.

[25] Balslev, S., Kristensen, A., 2005, Optics Express, 13, 344-351.

[26] Monat, C., Domachuk, P., Eggleton, B., 2007, Nature Photonics, 1, 106-114.

[27] Richter, M., 2004, Chem.Rev., 104, 3003-3036.

[28] Bezman, R., Faulkner, L. R., 1972, J. Am. Chem.Soc., 94, 6317-6323.

[29] Kim, J., Faulkner, L. R., 1988, J. Electroanal. Chem., 242, 107-121.

[30] Horiuchi,T., Niwa, O., Hatakenaka, N., 1998, Nature, 394, 659-661.

[31] Andrieux, C. P., Saveant, J.-M., Investigation of rates and mechanisms of reactions. In Techniques of chemistry; Bernasconi, C. F., Ed.; Wiley Interscience: New York, 1996; Vol 6, Part 2.

[32] Santhanam, K. S. V., Bard, A. J., 1966, J. Am. Chem. Soc., 88 (12), 2669-2675.

[33] Bard, A. J., Faulkner,L. R., Electrochemical methods, Wiley New York, 1980.

[34] Hazelrigg, M. J., Bard, A. J., 1973, ElectroAnal. Chem. Interf. Electrochem., 46, 141144.

[35] Sioda, R. E., 1968, J. Phys. Chem. 1968, 72, 7, 2322-2230.

[36] Evans, J. F., Blount, H. N., 1971, J. Org. Chem., 41(3), 516-519.

[37] Nadjo, L., Saveant, J.-M., 1971, J. Electroanal. Chem. Interfacial. Electrochem., 33, 419-451.

[38] Compton, R. G., Fisher, A. C., Wellington, R. G., Dobson, P. J., Leigh, P. A., 1993, J. Phys. Chem., 97, 10410-10415. 
[39] Levich, V. G. Physiochemical hydrodynamics, Englewood Cliffs, Prentice-Hall, Englewood Cliffs, New Jersey, 1962. 


\section{Scheme caption}

Scheme 1: Schematic cross view of the fluidic channel that integrates symmetrically two electrodes. The general mechanism for DPA annihilation ECL system is represented where DPA, $\mathrm{DPA}^{*}, \mathrm{DPA}^{\bullet+}, \mathrm{DPA}^{\bullet-}$ are the ground state, the excited state, the cation radical and the anion radical, respectively. Please note that the dimensions are not to the scale for a better view of the detection zone.

\section{Figure captions}

Fig. 1: a) A general view of the hand-held ECL chip with a $4 \times 4$ array of 16 optical sources.b) A scanning electron micrograph (SEM) of a couple of Ti/Pt/Ti microelectrodes spaced by $d=2 \mu \mathrm{m}$. c) A zoom at the end of electrodes.

Fig. 2: Cyclic voltammogramm of $5 \mathrm{mM}$ DPA in DMF containing $0.1 \mathrm{molL}^{-1} \mathrm{TBABF}_{4}$ at a $125 \mu \mathrm{m}$ Au electrode at $23^{\circ} \mathrm{C}$. Scan rate: $0.1 \mathrm{~V} / \mathrm{s}$, and start potential at $2 \mathrm{~V} / \mathrm{SCE}$.

Fig. 3: Cyclic voltammogramms of $25 \mathrm{mM}$ DPA in DMF containing $0.1 \mathrm{~mol} \mathrm{~L}^{-1} \mathrm{TBABF}_{4}$ measured with a separation distance $d=2 \mu \mathrm{m}$ at a static flow rate $F_{\mathrm{v}}=0 \mu \mathrm{L} \mathrm{s}^{-1}$. Scan rate: $0.1 \mathrm{~V} \mathrm{~s}^{-1}$. The blue areas show the voltage range where luminescence is observed. Inset shows a optical photograph of the ECL.

Fig. 4: Faradic current as a function of the time. Red curve: experimental values for a static volumetric flow rate $F_{\mathrm{v}}=0 \mu \mathrm{L} \mathrm{s}^{-1}$. Red dash curve: simulation of the Cottrell equation (fit parameters: $n=1, F=96485 \mathrm{C} \mathrm{mol}^{-1}, A=5.5 \times 10^{-3} \mathrm{~cm}^{2}, C=25 \times 10^{-6} \mathrm{~mol} \mathrm{~cm} \mathrm{~cm}^{-3}$ ). Green curve: experimental values for a constant volumetric flow rate $F_{\mathrm{v}}=0.1 \mu \mathrm{L} \mathrm{s}^{-1}$.

Fig. 5: Cyclic voltammetry of DPA in microfluidic chip. The solution contained $0.1 \mathrm{~mol} \mathrm{~L}^{-}$ ${ }^{1} \mathrm{TBABF}_{4}$ in DMF and $15 \mathrm{mM}$ DPA at $d=2 \mu \mathrm{m} \mathrm{Ti} / \mathrm{Pt} / \mathrm{Ti}$ microelectrode with a constant flow rate $F_{\mathrm{v}}=0.2 \mu \mathrm{Ls}^{-1}$ (Red curve and "unfolded" red dash curve). The green curve represents the PMT output voltage and the blue area shows the voltage range where luminescence is observed. 
Fig. 6: Electrical (left scale) and optical (right scale) chronoamperometric curve of DPA in microfluidic chip. The solution contained $0.1 \mathrm{~mol} \mathrm{~L}^{-1} \mathrm{TBABF}_{4}$ in DMF and $10 \mathrm{mM}$ DPA at $d=2 \mu \mathrm{m}$ and $d=10 \mu \mathrm{m} \mathrm{Ti} / \mathrm{Pt} / \mathrm{Ti}$ microelectrode with a constant flow rate $F_{\mathrm{v}}=0.2 \mu \mathrm{L} \mathrm{s}^{-1}$. 
Scheme 1

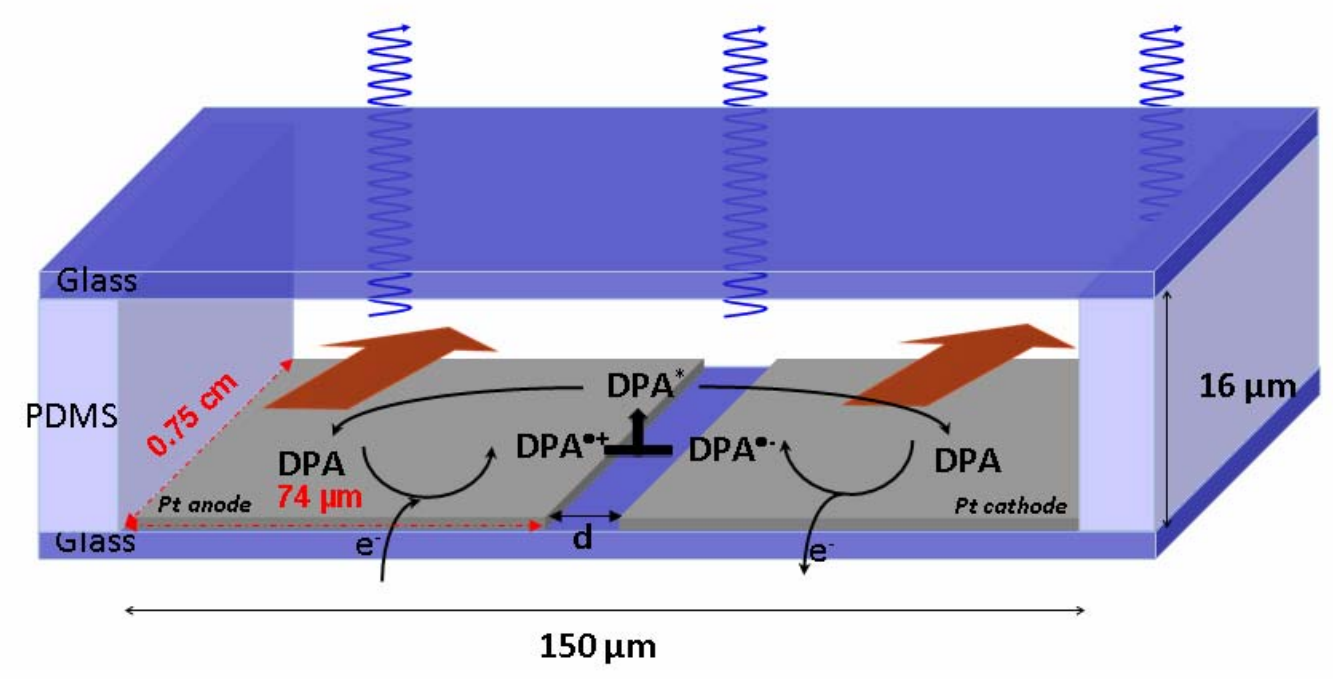


Figure 1

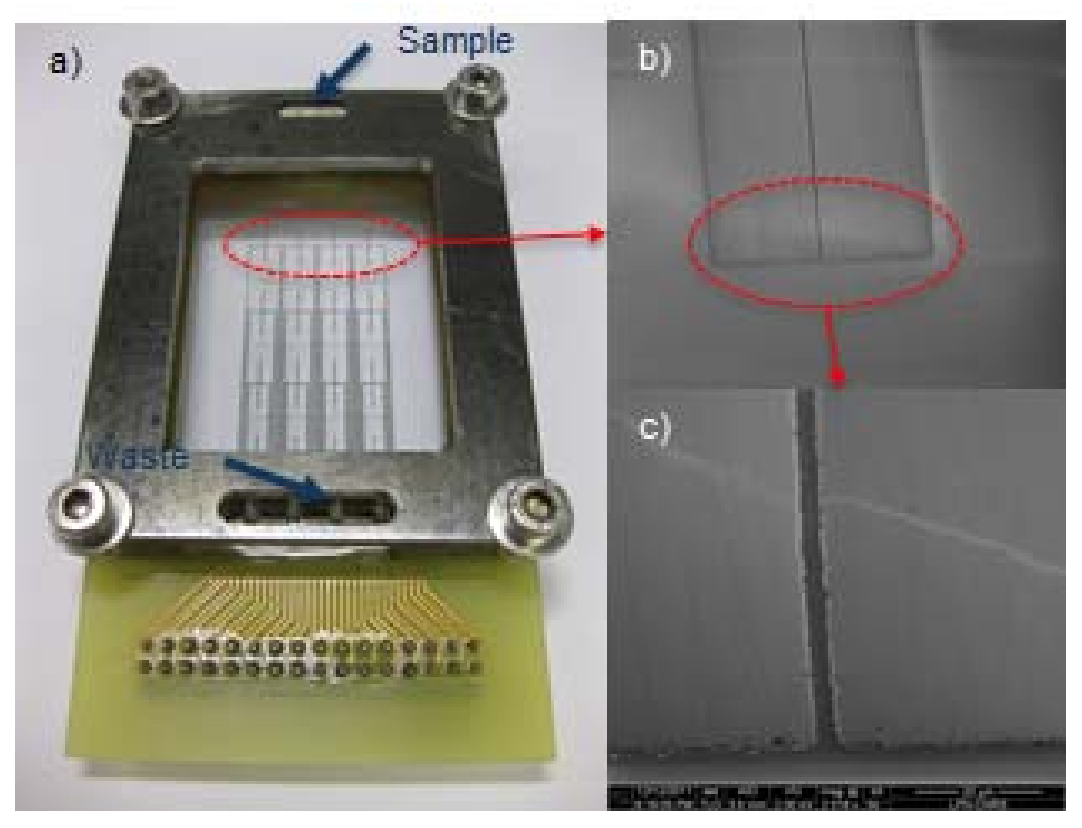


Figure 2

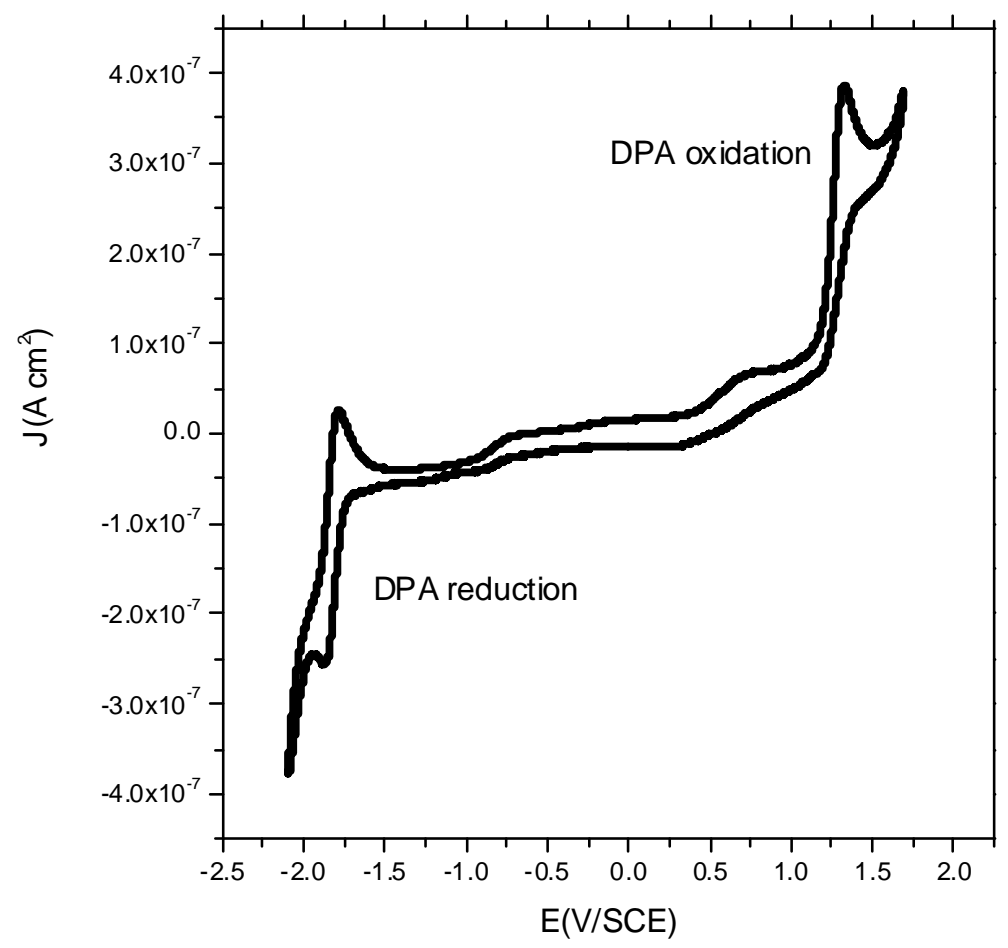


Figure 3

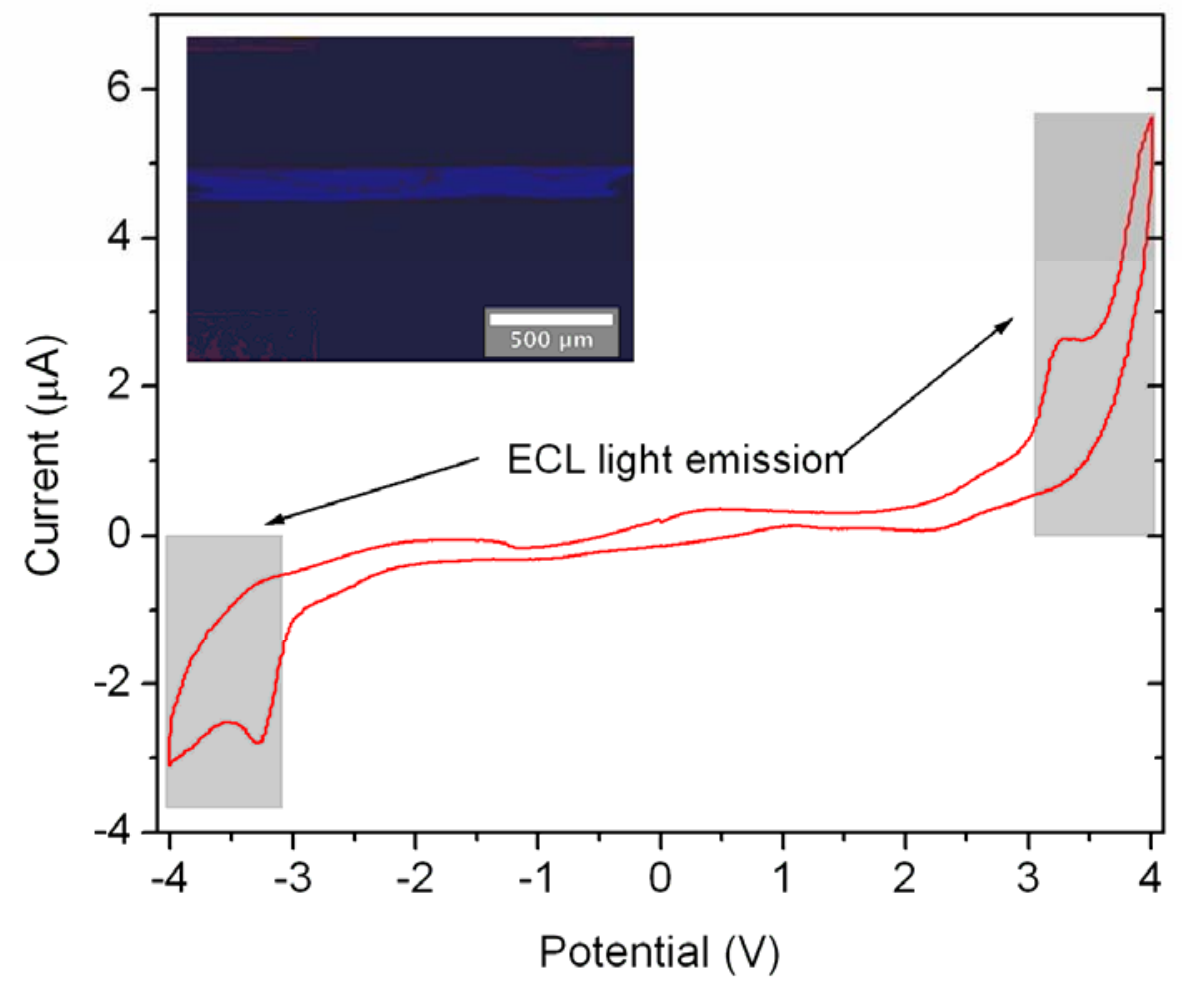


Figure 4

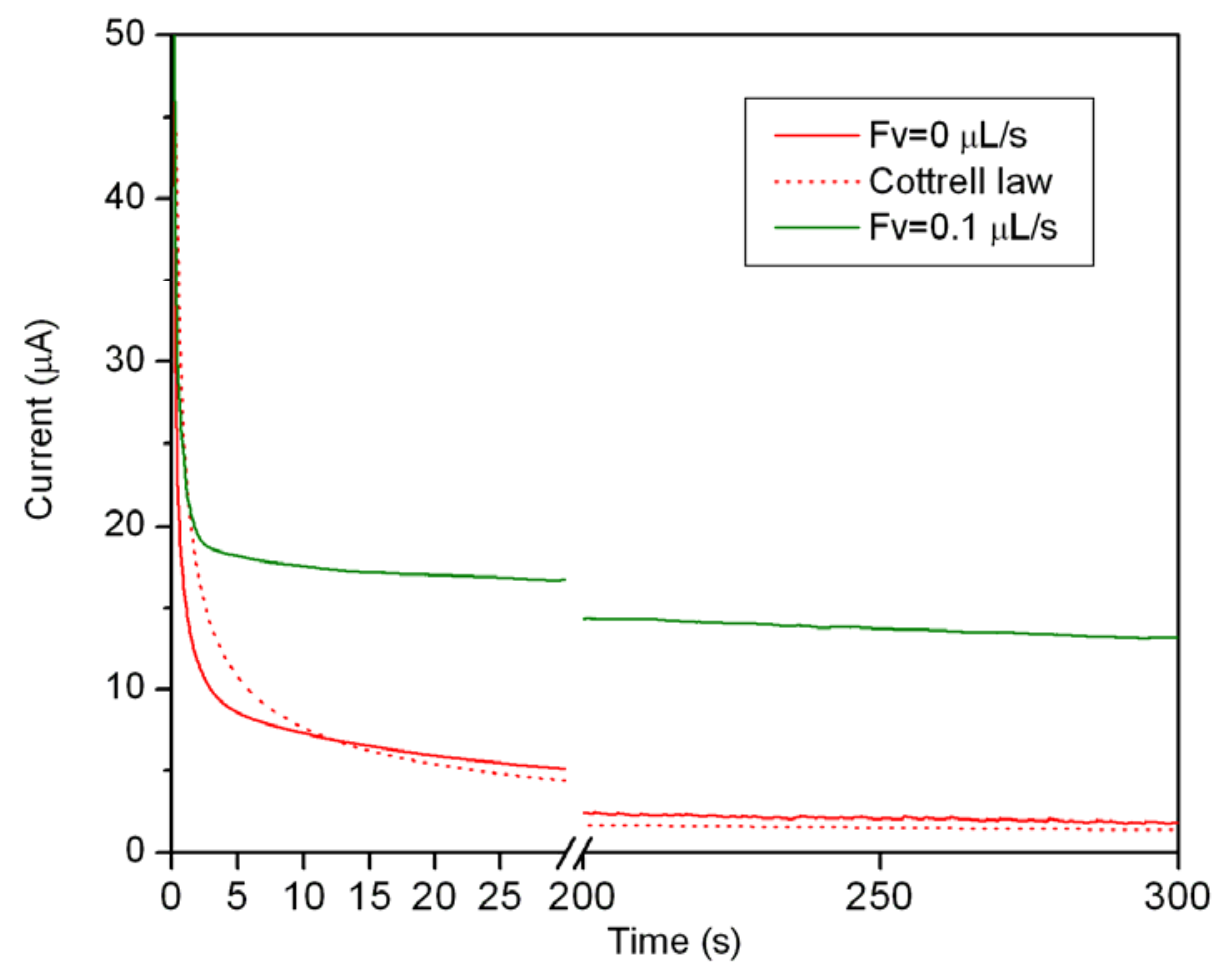


Figure 5

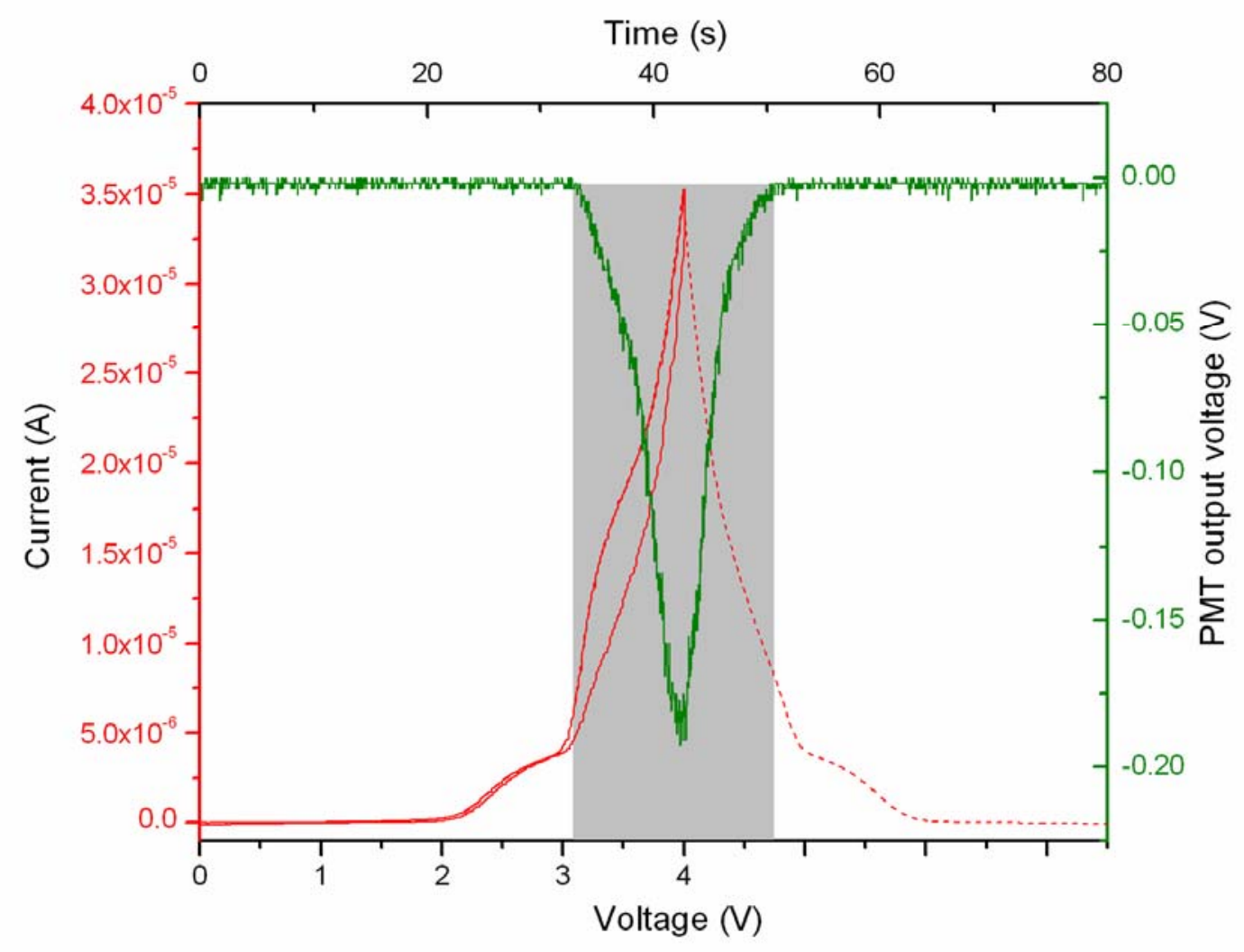


Figure 6

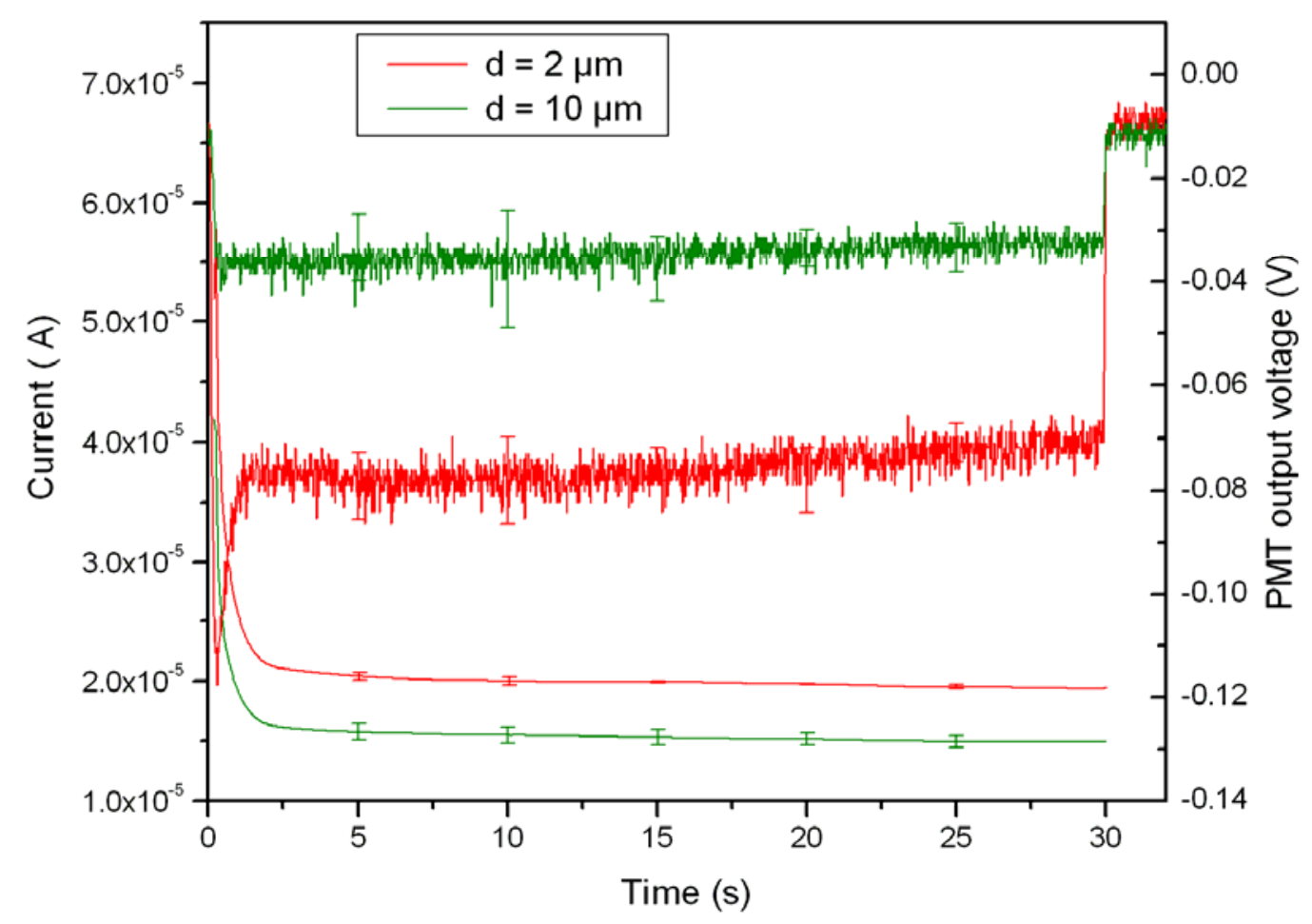

